\title{
PARAPLEGIA DUE TO INTERVERTEBRAL DISC LESIONS: A REVIEW OF 57 OPERATED CASES
}

\author{
By G. Ravichandran, M.B., F.R.C.S., Ed., and H. L. Frankel, M.B., F.R.C.P. \\ National Spinal Injuries Centre, Stoke Mandeville Hospital, Aylesbury, Bucks, U.K.
}

\begin{abstract}
In a review of 57 cases of paraplegia due to surgically confirmed disc protrusion (representing 0.9 per cent of all admissions to the National Spinal Injuries Centre), seven were in the cervical, $3 \mathrm{I}$ in the dorsal and $\mathrm{I} 9$ in the lumbar regions. Patients with dorsal disc protrusions treated by laminectomy had the worst neurological outcome. A recent decline in the incidence of neurological dysfunction following disc excision is noted and its probable causes discussed.
\end{abstract}

Key Words: Paraplegia; Intervertebral disc lesions; Post-operative neurological complications.

BACKPAIN due to prolapsed intervertebral disc is a common disease afflicting the industrialised Western population. Excision of such symptomatic discs is a common surgical procedure and one laminectomy is performed each year for every ten thousand population in England (Le Vay I967; Wood, 1976).

Key first reported a case of spinal cord injury arising from ruptured thoracic disc in I838. Gower (I892) described 'vertebral exostosis' which could compress the spinal cord or the nerves. The first clinical report of paraplegia due to dorsal disc protrusion appeared in I9I I (Middleton and Teacher). Soon many authors reported the particularly unfavourable outcome of surgical excision of dorsal disc protrusions, compared with prolapsed discs elsewhere in the spine (Mixter and Barr, I934; Logue, I952; Hulme, I960; Arseni and Nash, I960; Love and Schorn, I965; Ransohoff et al., I969 and Carson et al., I97I).

The present study was undertaken to assess in general the neurological damage associated with surgical excision of disc protrusions at all levels. A more detailed study of the neurological outcome associated with surgical excision of dorsal disc protrusions is included.

\section{Materials and Method}

The medical records of all patients admitted to the National Spinal Injuries Centre at Stoke Mandeville Hospital with a diagnosis of spinal cord paralysis related to spinal surgery; since its foundation in I944 until February I980, were examined. Of 105 case records, paralysis was associated with surgical excision of prolapsed intervertebral disc in 57 patients who are residents of the United Kingdom. All these records contained adequate details of the nature of illness and the operation performed from the referring hospital. Neurological charts at the time of admission and discharge were also available in most cases and in a few instances the charts from the referring hospital gave precise details of the initial symptomatology.

As this study is a retrospective one we had to use a simplified system of classification of the neurological status of the patients prior to disc excision and at the time of discharge from the National Spinal Injuries Centre. The classification 
consisted of five grades of neurological function denoted by the first five letters of the alphabet (Frankel et al., 1969) as shown below:

A Complete motor and sensory loss below the level of the lesion.

B Preservation of some sensation below the level of the lesion, possibly only sacral sparing but complete motor paralysis.

C Preservation of some motor power below the level of the lesion but of no practical use to the patient.

D Preservation of useful motor power below the lesion.

E Patient is free of neurological symptoms but may have abnormal signs.

\section{Results}

There were 23 women and 34 men who had spinal cord lesions associated with surgically confirmed disc protrusion. The youngest patient was a 30 -year-old woman and the oldest a 66-year-old man. Table I shows the incidence of disc protrusions at various regions of the vertebral column in this series. Fourteen patients had an acute onset of symptoms with gross neurological deficit occurring within 24 hours. Six patients reported trauma at work precipitating the onset of symptoms. Gradual onset of neurological dysfunction associated with backache, numbness and unsteady gait were the commonest symptoms. Paraplegia occurred instantly during straining at the toilet in five patients. Radicular pain was reported by all patients with lower lumbar disc protrusions. The time lapse from first symptoms and surgical excision of disc varied between 24 hours (six cases) and several years. There was no definite correlation between the time lapse before decompression and the final neurological lesion.

Tables 2 and 3 show the pre- and post-operative neurological status of the patients who have had dorsal or lumbar disc excision respectively. In this series neurological recovery occurred most commonly in patients who had lumbar disc excision. In recent years there has been a notable reduction in the number of patients admitted to the Spinal Injuries Centre whose neurological lesion was related to disc excision (Fig. I).

\section{Discussion}

Disc protrusions in the lumbar and cervical regions are relatively common and surgical excision of the symptomatic disc after adequate investigation has remained a sound surgical practice. Disc protrusions in the dorsal region are rare

\section{TABLE I}

Distribution of 6I surgically confirmed disc protrusions (57 patients). The discs correspond to those below the vertebral level.

\begin{tabular}{|c|c|c|c|c|c|c|c|c|c|c|c|c|c|}
\hline \multirow[b]{2}{*}{ Region } & \multirow[b]{2}{*}{ I } & \multicolumn{7}{|c|}{ Level of the disc } & \multirow[b]{2}{*}{9} & \multirow[b]{2}{*}{ IO } & \multirow[b]{2}{*}{ I I } & \multirow[b]{2}{*}{ I 2} & \multirow[b]{2}{*}{ Total } \\
\hline & & 2 & 3 & 4 & 5 & 6 & 7 & 8 & & & & & \\
\hline Cervical & & - & I & I & 4 & $I$ & - & & & & & & 7 \\
\hline Dorsal & & & 2 & - & 3 & 2 & 3 & 7 & 3 & 8 & 6 & I & 35 \\
\hline \multirow[t]{2}{*}{ Lumbar } & 2 & 2 & 3 & 6 & 6 & & & & & & & & I9 \\
\hline & \multicolumn{3}{|c|}{ Total } & & & & & & & & & & $6 I$ \\
\hline
\end{tabular}




\section{TABLE 2}

Pre- and post-operative neurological grading (Frankel et al., I969) of 3 I patients who have had surgical excision of dorsal disc protrusions. Figures in brackets represent the number of patients with disc protrusions between D.I and D.8. At least I7 patients were worse off following surgery and 8 were no better.

\begin{tabular}{|c|c|c|c|c|}
\hline $\begin{array}{c}\mathrm{AA} \\
6\end{array}$ & $\begin{array}{c}\mathrm{AB} \\
0\end{array}$ & $\begin{array}{c}\mathrm{AC} \\
1\end{array}$ & $\begin{array}{c}\mathrm{AD} \\
2\end{array}$ & $\begin{array}{c}\mathrm{AE} \\
1\end{array}$ \\
\hline $\mathrm{BA}$ & $\mathrm{BB}$ & $\mathrm{BC}$ & $\mathrm{BD}$ & $\mathrm{BE}$ \\
0 & 0 & 0 & 0 & 0 \\
\hline $\mathrm{CA}$ & $\mathrm{CB}$ & $\mathrm{CC}$ & $\mathrm{CD}$ & $\mathrm{CE}$ \\
0 & 0 & 0 & $2(1)$ & 0 \\
\hline $\mathrm{DA}$ & $\mathrm{DB}$ & $\mathrm{DC}$ & $\mathrm{DD}$ & $\mathrm{DE}$ \\
$14(6)$ & 1 & $2(1)$ & $2(1)$ & 0 \\
\hline $\mathrm{EA}$ & $\mathrm{EB}$ & $\mathrm{EC}$ & $\mathrm{ED}$ & $\mathrm{EE}$ \\
0 & 0 & 0 & 0 & 0 \\
\hline
\end{tabular}

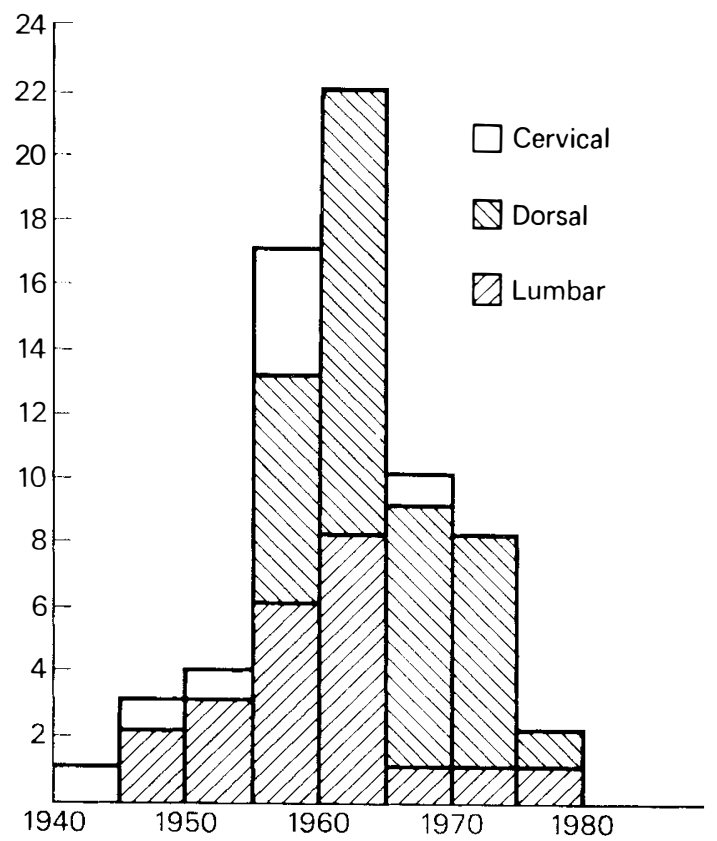

FIG. I

Histogram of patients admitted to the National Spinal Injuries Centre with neurological dysfunction associated with surgically confirmed disc protrusion between 1944 and 1980 . 
and continue to be difficult to diagnose and treat. This rarity was emphasised by Arseni et al. (1960), who reported that for every thousand disc excisions performed fewer than six were in the dorsal region. Carson et al., (I97I) believe that the true incidence of dorsal disc protrusion may be as high as one per million population per year. No meaningful idea of the incidence of neural dysfunction associated with disc excision could be made from our study, because over the period of this review various factors such as surgical and diagnostic techniques have changed radically. However, in the last Io years (Fig. I) there has been a dramatic fall in the number of patients admitted with neural dysfunction related to surgically confirmed disc protrusions. We believe this is largely due to prompt, adequate and technically superior surgical excision after necessary and appropriate preoperative investigation, carried out by trained people during the last decade.

In this series four out of seven cervical disc protrusions and 13 out of $3 \mathrm{I}$ dorsal disc protrusions occurred in women. However in the lumbar region there were I 3 men out of a total of I9 patients ( 69 per cent). This increased incidence of neural dysfunction following lumbar disc excision amongst men compares well with the reported 2: I ratio of men to women who undergo such surgical procedures (Spangfort, I972).

Even though cervical and lumbar disc protrusions are commonly encountered in clinical practice (Wilson et al., I977; Wood, 1979) in this series there were only seven cervical and I9 lumbar disc excisions which were associated with residual paralysis needing the care of a specialised institution. Four of the seven patients who had laminectomies for cervical disc protrusion were worse off following the surgery. On the other hand I I of I9 patients who had laminectomies for lumbar disc protrusion made good recovery, four others remained neurologically unaltered and only four were worse off following the surgery (Table 3). With over 6,000 low back operations being performed each year (Benn and Wood, I976) in the United Kingdom the incidence of neurological deficit associated with disc protrusion may

\section{TABLE 3}

Pre- and post-operative neurological grading (Frankel et al., 1969) of I9 patients who have had laminectomy for prolapsed lumbar disc. Eleven patients benefitted from the surgical procedure.

\begin{tabular}{|c|c|c|c|c|}
\hline $\begin{array}{c}A A \\
0\end{array}$ & $\begin{array}{c}A B \\
1\end{array}$ & $\begin{array}{c}A C \\
0\end{array}$ & $\begin{array}{c}A D \\
0\end{array}$ & $\begin{array}{c}A E \\
2\end{array}$ \\
\hline $\begin{array}{c}B A \\
0\end{array}$ & $\begin{array}{c}\mathrm{BB} \\
0\end{array}$ & $\begin{array}{c}\mathrm{BC} \\
0\end{array}$ & $\begin{array}{c}\mathrm{BD} \\
0\end{array}$ & $\begin{array}{c}\mathrm{BE} \\
0\end{array}$ \\
\hline $\mathrm{CA}$ & $\mathrm{CB}$ & $\mathrm{CC}$ & $\mathrm{CD}$ & $\mathrm{CE}$ \\
0 & 0 & 0 & 3 & 0 \\
\hline $\mathrm{DA}$ & $\mathrm{DB}$ & $\mathrm{DC}$ & $\mathrm{DD}$ & $\mathrm{DE}$ \\
1 & 0 & 3 & 4 & 5 \\
\hline $\mathrm{EA}$ & $\mathrm{EB}$ & $\mathrm{EC}$ & $\mathrm{ED}$ & $\mathrm{EE}$ \\
0 & 0 & 0 & 0 & 0 \\
\hline
\end{tabular}


TABLE 4

Neurological consequences following various surgical techniques employed for removal of dorsal discs in 31 patients (35 discs).

\begin{tabular}{lccc}
\hline & Improved & Unchanged & Worse \\
\hline Laminectomy & 7 & 6 & I2 \\
Posterolateral & I & I & 0 \\
Decompression & I & I & 4 \\
Costo Transversectomy & 0 & 0 & 2 \\
Anterolateral & 0 & 0 \\
\hline Decompression & &
\end{tabular}

appear to be extremely low. It must be pointed out that only patients with gross paralysis requiring rehabilitation are admitted to the National Spinal Injuries Centre.

There were 3 I patients who had paraplegia that was associated with dorsal disc protrusion of whom 25 were treated by laminectomy (Table 4). This procedure had a singularly bad result, an observation that has been recorded by many neurosurgeons. While it is difficult to estimate the actual number of dorsal disc protrusions that needed excision during the period of this study the notable fall in the overall incidence of paraplegia following dorsal discectomy as seen in the National Spinal Injuries Centre, suggests a change in the morbidity rate associated with this procedure. There are confusing and often conflicting accounts on the merits of laminectomy for dorsal disc protrusion in the medical literature (Singounas et al., I977; Paini et al., 1978; Ongerboer de Visser et al., I978; Kertschmer et al., 1979). Transthoracic removal of the disc (Ransohoff et al., 1969, and Perot et al., I969) has been claimed to produce minimal complications by some authors while others favour a modified form of costotransversectomy (Hulme, I960) or posterolateral decompression (Benson et al., 1975). In our review the fact that very few patients with dorsal disc protrusion had neurological complications in association with either costotransversectomy or posterolateral decompression (Table 4) may suggest a better prognosis with these surgical procedures compared with laminectomy. Furthermore, since the publication of these decompressive procedures for dorsal disc protrusions very few cases have been referred to this centre with paralysis associated with dorsal disc excision (Fig. I).

From the records available it was not possible to ascertain if any preventable errors had occurred during surgery, contributing to neural dysfunction. All dorsal disc excisions were carried out in neurosurgical centres. There were I 5 neurosurgical centres that had referred patients to the National Spinal Injuries Centre, but nearly a third (I I patients) came from two neurosurgical centres which are the largest of their kind in England. These two centres have been in existence for the longest period of time and they handle a disproprotionately large number of neurosurgical cases.

There were only two cases of upper dorsal (D.I-D.4) disc protrusions in this series one of who improved following laminectomy. Of seven patients with mid dorsal disc protrusions (D.5-D.8) six were worse off following discectomy and the other was no better (Table 2). More complications appear to be associated with laminectomy than any other form of surgical excision of the dorsal disc.

It is generally believed by many neurosurgeons that any compression of the spinal cord should be relieved as soon as possible for optimal chance of recovery.

$19 / 3-B$ 
None of the patients in this series was decompressed within 24 hours from the onset of symptoms. So we cannot provide conclusions on the benefit of early surgery. It is possible that such decompressions did produce good functional recovery, not requiring the attention of a spinal injuries centre. Among those who had decompressive procedures within 48 hours, three out of seven with dorsal, and six out of nine with lumbar disc protrusions improved neurologically. Five out of 19 patients with dorsal disc protrusion and nine out of ten with lumbar disc protrusions in whom decompressive procedures were carried out several days after the onset of symptoms also made satisfactory neurological recovery. Thus the time interval between the onset of symptoms and spinal decompression did not bear any direct relation to the final neurological status in this review.

Two patients developed syringomyelia several years after the initial operation for mid dorsal disc protrusion. At the time of the onset of the symptoms one patient had a myelographic block at D.6 with a sensory level at D.8. The disc excision was done through a postro-lateral approach (lateral rochotomy). The patient's neurological state became worse post-operatively and developed a complete D.6 paraplegia. The syringomyelia developed gradually and was confirmed by cisternal myelography.

The second patient presented in 1970 with a D.6 partial Brown-Sequard lesion, and the neurological disability became worse for six weeks after a D.5-D.6 laminectomy for prolapsed dorsal disc, then subsequently improved. Two years later, a cisternal myelogram was done to investigate a progressive increase in spasticity. The investigation revealed a wide block at the previous laminectomy site. Excision of the dura over a $3 \mathrm{~cm}$. length together with a freeze-dried dural graft, produced a remission in symptoms for six months. When re-explored for another relapse that followed, a large syringomyelitic cavity was noted and that patient became totally paralysed below D.5 thereafter.

Two other patients had re-exploration of the laminectomy site, the day following the operation, either because of the dense paralysis that had ensued, or to verify if the decompression was adequate. Another patient had three spinal operations, a laminectomy, a costotransversectomy and an operation to verify the site, on three consecutive days!

Patients who had a laminectomy for lumbar disc protrusions generally had a disturbance of micturition. As can be seen from Table 3, most of these patients improved during a short period of bladder rehabilitation at this spinal injuries centre.

\section{RÉSUMÉ}

Analysant 57 des cas de paraplégie qui sont causés par des protrusions du disque intervertébral-confirmés chirurgicallement-on a trouvé que ces cas font $0.9 \%$ de toutes les admissions dans le centre national de la paraplégie. On en a trouvé sept dans la région cervicale, 3 I dans la région thoracique et 19 dans la région lombaire.

Les patients dont la protrusion du disque thoracique avait été traitée par une laminectomie avaient le plus mauvais résultat neurologique.

On a noté cette recent réduction des dysfunctions (malfonctions) neurologiques apres une excision des disques intervertébraux et les cas possibles de cette réduction sont discutés.

\section{ZUSAMMENFASSUNG}

Bei der Nachprüfung von 57 Paraplegie-Fällen die durch chirurgisch bestätigte Discus-Protrusionen hervorgerufen worden sind, ergibt sich, dass diese Fälle $0.9 \%$ aller Einweisungen in das nationale Querschnitts-zentrum darstellen. Davon waren $7 \mathrm{im}$ cervicalen, $3 \mathrm{I}$ im thorakalen und 19 im lumbalen Bereiche. 
Patienten, bie denen die thorakale Discus-Protrusion durch eine Laminektomie behnadelt worden war, hatten das schlechteste neurologische Ergebnis.

Man hat die jüngste Abnahme des Vorkommens einer neurologischen Dysfunktion nach einer Discus-Excision zur Kenntnis genommen, und die möglichen Ursachen dieser Abnahme werden diskutiert.

\section{REFERENCES}

ARSENI, C. \& Nash, F. (1960). Thoracic intervertebral disc protrusion. F. Neurosurg., 17, $4 \mathrm{I} 8-430$.

Benson, M. R. D. \& Byrnes, D. P. (I975). The clinical syndromes and surgical treatment of thoracic intervertebral disc prolapse. F. Bone Ft. Surg., 57B, 47 I-477.

BenN, R. T. \& Wood, P. H. N. (I975). Pain in the back. An attempt to estimate the size of the problem. Rheumatol. Rehabil., I4, I2 I-I 28.

Carson, J., Gumpert, J. \& JefFerson, A. (I97I). Diagnosis and treatment of thoracic intervertebral disc protrusions. F. Neurol. Neurosurg. Psychiat., 34, 68-77.

Frankel, H. L., Hancock, G., Hyslop, J., Melsak, J. S., Michaelis, L. S., Ungar, G. H., VERNON, J. D. S. \& WALSH, J. J. (I 969). The value of postural reduction in the initial management of closed injuries of the spine with paraplegia and tetraplegia. Paraplegia, 7, I79-192.

Gowers, N. R. (1892). Diseases of the Nervous System, 2nd. ed., Vol. I, p. 260, Churchill, London.

Hulme, A. (1960). The surgical approach to thoracic intervertebral disc protrusions. F. Neurol. Neurosurg. Psychiat., 23, 133-135.

KeY, C. A. (I838). On paraplegia depending on disease of the ligaments of the spine. Guys Hospital Rep., 3, I7-34.

KRETSCHMER, H. \& GUSTORF, R. (I979). Zur Problematik Der Thorakalen Bandscheibenvorfalle. Neurochirurgie, 22, 4I-47.

LE VAY, D. (1967). A survey of surgical treatment of lumbar disc prolapse in the United Kingdom and Eire. Lancet, I, I2I I-I 2 I3.

Logue, V. (I952). Thoracic intervertebral disc prolapse with spinal cord compression. F. Neurol. Neurosurg. Psychiat., 15, 227-24I.

LOVE, J. G. \& SchORN, V. G. (1965). Thoracic disc protrusions. F.A.M.A., 191, 8, 627-63I.

MidDleton, G. S. \& TEACHER, J. H. (I9II). Injury of the spinal cord due to rupture of an intervertebral disc during muscular effort. Glasgow Med. F., 76, I-6.

MIXTER, W. J. \& BARR, J. S. (I 934). Rupture of the intervertebral disc with involvement of the spinal canal. New Engl. F. Med., 211 , 2 IO-215.

Orgerboer De Visser, B. W., Moffie, D., Lange, J. \& Lunding, J (I978). Thoracle hernia nuclei pulposi. Ned. T. Genesk, 122, 539-542.

Paini, G. P., Baldi, P. G., Giovanni, T., Passoni, M. \& Barra, N. (1978). Ernie Discali Dorsali. Acta Bio. Med., 49, 25-36.

Perot, P. L. \& MunRo, D. D. (I969). Transthoracic removal of mid line thoracic disc protrusions causing spinal cord compression. F. Neurosurg., 3I, 452-458.

RANSOHOFF, J., SPENCER, F., SIEW, F. \& GAGE, L. (I969). Transthoracic removal of thoracic disc. F. Neurosurg., 3I, 459-46I.

Singounas, E. G. \& Karvounis, P. C. (1977). Thoracic disc protrusion. Acta Neurochirurgica, 39, $25 \mathrm{I}-258$.

SPANGFORT, E. V. (I972). The lumbar disc herniation-a computer aided analysis 2504 questions. Acta Orthop. Scand., (Suppl.) 142.

Wilson, D. H. \& CAMPBell, D. D. (I977). Anterior cervical discectomy without bone graft. F. Neurosurg., 47, 55I-555.

Wood, J. P. (I979). Laminectomy-is it worth it? F.A.O.A., 78, 671-678.

Wood, P. H. N. (1976). Epidemiology of back pain $13-17$, in the Lumbarspine and Backpain, Ed. Malcolm Jayson, Sector Publishing Limited, London. 